\title{
The Co-Creation of Locally Useful Knowledge by Business Schools
}

Simon Mosey, Paul Kirkham and Martin Binks.

\begin{abstract}
In the UK, Business Schools are being exhorted by government to engage with local organizations to enhance their competitiveness. However, a historical legacy of providing courses for international students and a research focus upon multi-national firms has constrained the capability of most business schools to contribute in this way. We highlight global examples of business schools recognising the opportunity to develop locally useful knowledge and enhance the capabilities of their students to deploy that knowledge. Business Schools are seen to significantly reposition their offer by developing the leadership skills of local organizations and enhancing the entrepreneurial and problem solving skills of their students for local deployment. We conclude that a sustained emphasis upon faculty and student engagement with local organisations can allow business schools to overcome legacy constraints and thereby contribute more fully to local economic competitiveness for mutual benefit.
\end{abstract}

\section{Keywords}

Business school, local knowledge, co-creation, local competitiveness.

\section{$<1>$ The historical role of business schools}

The first business school was founded in Paris where in 1819 a group of scholars and businessmen, including the economist Jean-Baptiste Say, founded the Ecole Spéciale de Commerce et d'Industrie (now known as the Ecole Supérieure de Commerce de Paris, ESPC). In common with many early business schools the primary role was upon teaching and, more specifically for ESPC, language education was a central component to allow 
students to participate in the international trade prevalent in Paris at the time. ESPC also provided classes for local entrepreneurs with Say developing one of the early definitions of an entrepreneur as someone who unites all the means of production (Say, cited in Kitchener, 2001, p. 61).

Over time ESCP grew and developed a culture of research and today has 950 staff and over 4000 postgraduate students. As in most world leading business schools the majority of the students are international and the primary research focus is upon multinational businesses.

Whilst many students commonly state ambitions to work for such blue chip companies, the simple fact is that most of them will not. Some of the best and most dynamic will start their own businesses, often close to their alma mater. Many others will make their livings in small and medium sized enterprises; many of which will be family firms rooted in local economies.

We therefore question the relevance of much of what is taught in modern business schools, particularly with reference to the needs of the local economy. It is difficult to see how theories based on such a narrow focus prepare students for what they will face in practice.

This is reinforced by Starkey et al (2004) who report the case of the Dean of a University of California management school who realised that her most useful knowledge 'came primarily from engagement with and listening to practising managers, not from the scholarly work emanating in such quantities from the academy.'

A long time advocate of a broader, more dynamic approach is Roger Martin, former Dean of the Rotman Business School, who argues:

"As a whole, MBA programs have taught students a suite of tested and trusted models, but left unanswered the problem of what to do when those models don't apply or start to break down. As a result, we have left our graduates under-prepared to 
function in the ethically-murky, complex world outside of the classroom." Martin (2010, p17)

Martin prescribes a significant change in research focus to be necessary for business schools to survive. He proposes a transition towards understanding the creation of new business rather than the current obsession with describing the activities of multinational businesses. Yet, Martin argues, business schools are self-satisfied and have little incentive to change their focus due to their phenomenal financial success. For instance, in the US business schools have exhibited massive growth in the last 100 years from zero to $30 \%$ of the market by student numbers and from zero to $50 \%$ by revenue (Martin, 2013). However he confidently predicts the imminent and abrupt collapse of this market.

"Half of U.S. business schools will be out of business in five to seven years because of online disruption," Martin (2013b).

At the same forum Clayton Christensen, a management professor at Harvard Business School warned:

"The advent of online learning, and the propensity of more and more companies to bring teaching of management in-house, versus outsourcing it, makes disruption a very big deal for business schools," Christensen (2013).

The twin threats of internal redundancy and external disruption suggest it might be time to change. It would be somewhat ironic if Business schools, with all their theoretical knowledge of entrepreneurship and creative destruction, were unable to rise to the challenge. Such a transition is profound, however, as it requires a paradigm change in the nature of the majority of research conducted, not only in terms of the content but also the method of study. Research considering international business is observational in nature after which the findings are abstracted and disseminated to students. The direction of flow of knowledge in business school teaching is from the master to the apprentice. The nature of the knowledge 
imparted tends to be static, it is 'ancient wisdom' to be passed on as a canon along with interpretation.

Historically, in at least one school within the University, the flow does run both ways. In the case of a medical school the transaction is obvious - 'I'll cure you of that nasty little rash if you let my students have a look at how I do it'. This is fairly one-sided, the patient is in no fit state to bargain, but the benefits are concrete.

A first step for Business schools may therefore be to build similar relationships with local organizations. They need to engage with small businesses in order to study them, but what do they offer in return? Research suggests that, in the rare instance, when business schools engage with the local firms they have comparatively little to offer (Lucas, 2011).

A series of policy reports from the UK government have commented upon this disconnect:

'There is still a gap between what the UK further and higher education system provides, and what manufacturers need.' Lucas (2011,p.5).

And there are '...complaints that universities are often hard to work with, and the fact that too much research undertaken in the UK higher education does not find its way into viable British companies.' Lucas (2011,p.17).

According to the Confederation of British Industry 'only 10 per cent of innovative enterprises in the UK cooperate with a university or another higher education institution' Wainer $(2009$, p.25).

The UK government response has been to address this disconnect as a 'market failure' and provide sources of funding to incentivise business schools and local businesses to work more closely together (Young, 2013). 


\section{<1>Opportunities for Business Schools to Engage Locally}

Wilson (2012, p.23) summarised the potential value that universities can bring to the local economy in the UK:

'Universities are an integral part of the supply chain to business, a supply chain that has the capability to support business health and therefore economic prosperity. A thriving knowledge economy depends upon its universities in three critical dimensions: the application and exploitation of research capability; the enterprise and entrepreneurial culture that is developed amongst its students; and the applicability of the knowledge and skills of all its graduates.'

Specifically considering business schools, Cox (2013) highlighted the main opportunities for engagement to be in skills development programmes, knowledge transfer and consultancy, access to graduate talent, networking, strategic research and development. However, she observes that medium sized local businesses already had sophisticated training plans and were utilising a blend of individual trainers, small businesses and internal trainers for their delivery. Business schools reported a relatively small market share of this business with less than $10 \%$ of such businesses opting for university providers.

A more optimistic view of the potential of business schools to contribute towards local economic impact is proposed to be through the mobilisation of students:

'There are currently in the region of 130 business schools in the UK, the majority of which belong to universities. They have been one of the biggest success stories of UK higher education over the past 60 years, enjoying a remarkable rise: in $201015 \%$ of all HE students in the UK were studying business and management in publicly funded UK universities (at foundation, undergraduate and postgraduate levels), and another 20,000 in private institutions. This arguably makes Business and Management Studies the largest academic provider of talent in the UK with an extensive skills and knowledge base.' Cox (2012, p.5) 
This resonates with the research of Salter and Martin (2001) who conclude that the largest economic impact that universities provide is through the provision of students with advanced knowledge and the capabilities to apply that knowledge to solve industry problems. In the following section we therefore consider examples of business schools from around the world that have recognised new opportunities to develop locally useful knowledge and built faculty and student capabilities to deploy that knowledge.

\section{<1>Developing Locally Useful Knowledge within Business Schools}

It is apparent that the development of locally useful knowledge is a significant challenge for modern Business Schools. Here we define useful knowledge following Kuznets (1971) as being generated through the interaction of basic and applied research with societal challenges. Business Schools are often criticised for their shortfall in this domain yet Business Schools can and do develop such knowledge and use it to form the basis of two-way exchange with local companies. The ideal is for a business school to be a mediator and cocreator of knowledge (Lourenco et al, 2013).

The following case example illustrates the principle:

Kay and Jonathan are in the floristry trade in a large provincial market town. Although they own the freehold to four shops, inherited from Kay's father, life is increasingly tough. At an executive education workshop hosted by Nottingham University Business School, in the UK, they summed up their challenge thus: 'How to compete effectively in a market with low profit margins'.

Possible solutions fell into two categories - those which concentrated on more efficient use of their staff and premises, and those which sought to add value by expanding the services they could offer to differentiate them from the competition, using facilities and competencies that were unavailable to their rivals. Examples 
included diversification of the business into provision of flower-arranging classes, a café/teashop and an expanded delivery service.

It became obvious to observers that floristry was an extremely tough business. Profit margins were around $16 \%$, while wastage in raw materials could easily top 10\%. The competition came from both sides: large supermarkets, where economies of scale forced down prices, and also smaller, home-based enterprises with minimal overheads. This concrete example made it easy to introduce the concept of 'Blue Ocean Strategy' (Kim and Mauborgne, 2005) as well as research from Scott Shane that typical start-up 'entrepreneurs' work longer hours for less money and that many such businesses start with around \$25,000 worth of investment and only last for about two years (Shane, 2007). And so it became clear that not only are Kay and Jonathan competing against the might of big business, they are also competing against individuals working out of their spare rooms and garages, a considerable number of whom, despite their best efforts, after a period of operating at a loss on the margins of legality, are statistically certain to go bust1. When an inefficient business goes under there is a knock-on effect as the remaining, more efficient competitors find their market swamped with bankrupt stock and second-hand machinery. Competition of this sort can easily drag down whole areas of business.

The value realised from this transaction is that the participating faculty gained a new case study, the business owners learnt some relevant and contextualised theory that they could put into practice and all participants gained fresh insights into the day-to-day problems of local small businesses - real knowledge exchange and the co-creation of new, locally useful knowledge. 
This is particular case but not an isolated example. Lancaster University Management School, in the UK, has engaged in such activities for many years and their research shows that when engagement occurs and useful local knowledge exchanged there is a measureable benefit for the local economy. They developed a programme called Leading Enterprise And Development (LEAD). This was initially supported by funding from the local government for Management School faculty to engage with local small business owner-managers, using pedagogical techniques such as experiential learning and providing additional support through mentoring and staff exchanges. The programme grew, was adopted by other regional Business Schools and demonstrated a significant return upon the public sector investment. Over 1,000 high growth businesses have been supported across the North West and external evaluation has shown that every $£ 8 \mathrm{k}$ invested generated average turnover growth per business of $£ 200 \mathrm{k}$. (Cox, 2012)

The efficacy of faculty providing locally useful knowledge is clearly evident, yet such impact is ultimately limited by the number of faculty. As Salter and Martin () suggest, perhaps even greater economic impact could be delivered locally through involving the much larger student body.

\section{<1>Developing the Capabilities of Students to Deploy Locally Useful Knowledge}

It might be remarked that knowledge exchange with a florist is beneath an august institution like a business school and its privileged students but the vast majority of businesses in virtually all sectors are small and confront similar constraints, conditions and opportunities. It is the richness of their experience in practice that is so valuable as a source of learning for students of business. 'Live' case studies preferably imparted by the businesses concerned, are a powerful and memorable source of understanding akin to laboratory studies in many of the pure sciences. The businesses gain as well. It is worth restating the obvious point that every large business started out as a small business. Business 
Schools are, on the one hand, producing the future giants of business who all want blue chip company internships on their CVs. On the other they are producing the entrepreneurs of the future who only want to work for themselves. Yet statistically, most businesses lie in between these atypical extremes:

'The UK's 3 million family businesses represent two in three of all private sector firms and account for a quarter of UK GDP,' Cox (2012,p. 21)

Upon graduation, business school students employed in these firms, may find themselves to be the only graduate on the payroll and so it is essential that they gain experience at all levels of business. Many students attending UK business schools, perhaps a majority of overseas students, will end up working for a family business, where practical wisdom and dealing with ambiguity are as vital as accountancy knowledge.

Yet the delivery of such practical wisdom requires a profound change in teaching and learning approaches. It requires an integrative learning experience "... whereby knowledge is created through the transformation of experience" (Kolb, 1984, p. 41). This builds on the assumptions that such learning is a process, not an outcome; requires individuals to resolve dialectically opposed demands; is holistic and integrative and requires interplay between a person and the environment (Kayes, 2002, p.140). This is in stark contrast to Business School practice where undergraduates sit in darkened lecture theatres and focus upon abstract theory and hone their skills at writing essays critically discussing such theory (Binks et al., 2006; Mintzberg, 2004; Holcomb et al., 2009).

It is notable, therefore, to observe leading US Business Schools pioneering practical knowledge based pedagogical interventions. For example, at Stanford University students learn through immersion in actual rather than theoretical business. Their module Technology Entrepreneurship and the Lean Startup has the goal to "Provide an experiential learning opportunity for engineers to see how entrepreneurs really build companies. In ten weeks, 
teach a four-person team how to transform a technology idea into a venture-scale business opportunity. Do it by having them get outside the classroom and test each element of their business model." (http://e245.stanford.edu/)

On his website supervising professor Steve Blank states 'Congratulations to all the teams. They taught us a lot.'

Another example is The Yale Entrepreneurial Institute which started as a stand alone programme in 2007 to encourage students to start scalable new ventures. As YEI Program Director Alena Gribskov tells students:: "There's no substitute for talking to customers. It can be very anxiety-inducing, because you have to talk to strangers. But until you do, you will not have real data -- you will only have assumptions." (http://yei.yale.edu/)

It is interesting that both Stanford and Yale are pioneers of Massive Online open Courses (MOOCs), demonstrating that internationalism and localism are not necessarily mutually exclusive.

Such practice has also been adopted by US business schools based within areas suffering from economic decline, where a focus upon local issues has provided additional value for students. Alison Davis Blake, Dean of Michigan Ross School of Business, argues that her students '.....need to discover their own purpose, we need to test the assumption that our students are adults and know why they are here. They need to learn how to create purpose and meaning for others with whom they work and learn how to use the power of the firm to address complex societal problems,' Davis Blake (2013)

Similarly in the UK, faculty are recognising the need for practical immersion in local business challenges by students where an ambitious approach has been created, developed and refined over the last ten years at Nottingham University Business School. Here every undergraduate takes a course presenting a formal analysis of entrepreneurship in theory and practice leading on to a consideration of creativity and business concept generation. The 
course concludes with the practical application of these theories and concepts in business planning and business concept presentation.

Students are challenged to identify a problem, need or opportunity and propose a business solution, be it a new product or service, to 'pitch' to their assessors.

It would be impossible to teach this course without the involvement of local entrepreneurs and business people who take a central role in mentoring the students to help define societal challenges and evaluate new business ideas to address those challenges.

From the examples above it is apparent that students can be mobilised to work on local business challenges and work with local business people to develop new business ideas, yet it is less clear how such approaches can be adopted to the extent suggested by the UK government (Witty, 2013).

\section{Economy. \\ $<1>$ Recognising the Opportunity for Business Schools to Engage with the Local \\ Of all the schools within the university, Business Schools should be best placed to} recognise new opportunities within the market, a capability Kirzner (1985) argued to be the essence of entrepreneurship. First, business schools often maintain considerably autonomy over resource allocation that other schools envy. Second, they are typically the home of the rapidly growing field of entrepreneurship education, with Katz (2003) reporting over 2200 courses in entrepreneurship being taught worldwide.

Yet there seems to be a disconnect between the teaching and the practice of entrepreneurship by business school faculty. It appears that in their haste to meet the increasing demand for entrepreneurship teaching, business schools have recruited adjunct faculty that are subsequently excluded from strategic decision making by business school leaders (Hebert and Link, 2006). Such leadership remains dominated by research professors 
intent upon preserving historical traditions. Moreover, even when entrepreneurial leaders are recruited to instigate change, they encounter considerable resistance from faculty.

Roger Martin eloquently categorises the barriers to change within the majority of Business Schools worldwide. He argues that it is difficult to change faculty attitudes as they typically get paid double the salary of comparable social scientists elsewhere in the university. When leading Rotman School he encountered faculty that would '...fight to the death if I took anything off them and asked them to try something new even if they ultimately would perish in the process,' (Martin, 2013). Martin observed, however, that younger faculty could be encouraged to work in a different way and could be supported by non tenured staff to help them to deliver small business and entrepreneurship offers. Through pursuing this strategy Martin grew the Rotman school from a $\$ 13 \mathrm{~m}$ to $\$ 130 \mathrm{~m}$ annual turnover.

A different approach to achieve a similar outcome was seen in Italy where Bocconi have created a competence centre in public private interaction, where they act as link between academe, local authorities and businesses. Here faculty and students work on projects to help public sector managers to encourage entrepreneurship in local schools, hospitals and civil services. Nevertheless, Bocconi have encountered more difficulty than Rotman with scaling up this approach due to the lack of political stability and hence sustained external resources to grow the centre (Cennamo, 2013).

A contrasting and more radical approach is seen in Canada, where Quebec Seeks Solutions (QSS) was launched in June 2010. This enterprise is a combination of online and face-to-face open innovation. It is a four stage process: first is an online 'call for problems' from local businesses and public sector organisations. From these a selection is made by the organisers. The third stage is to describe and broadcast these problems and failed solutions through a web-based platform, in order to recruit the best problem solvers available from faculty and students. Finally a showcase event in the form of a conference was held to share 
insights and solutions. The most apparent gain for all was networking but very real solutions have resulted. Further events have been held both at home in Canada and abroad, in Finland and Spain.

The natural home for this sort of model of co-creation of new knowledge, relevant and supportive of the local economy, ought to be the local Business school. Alongside the economic benefits and learning opportunities that this integration of students with their subject matter engender, the research potential is clearly invaluable and unique.

\section{Conclusions}

Business Schools internationally stand at a crossroads. They face Clayton Cristensen's 'innovator's dilemma' of balancing the continuation of their legacy offer with developing a disruptive proposition (Christensen, 1997). We highlight examples of Business schools that are experimenting with disruption and see that by providing sustained leadership for the development of locally useful knowledge they can, somewhat counter-intuitively, survive the short-term vagaries of local political support.

Moreover, the key to scaling and sustaining such activity seems to be within the student body. If business schools reposition their teaching and learning towards more experiential methods where students work together with local leaders to address small business growth challenges, create valuable new ventures and encourage entrepreneurship within the public sector then this can provide a source of income that transcends the turbulence of the international student markets. 


\section{References}

Binks M, Starkey K and Mahon C (2006) Entrepreneurship Education and the Business School Technology Analysis and Strategic Management 18(1): 1-18.

Christensen, C. M. (1997). The Innovators Dilemma. Harvard Business School Press. Boston, MA, USA.

Christensen, C. (2013). The future of Management Education, Thinkers 50 Forum, London, 2013.

Cennamo, C. (2013). Sustainable Enterprise Models Innovation. Academy of Management Conference, Orlando, 2013.

Cox, S (2012). Business School/Mid-Sized Business Collaboration-Supporting Growth in the UK's Mid-Sized Businesses, Report for Business Innovation and Skills, London, UK.

Davis Blake, A. (2013). The Future of Business and the Role of Business Education, Academy of Management Conference, Orlando, 2013.

Hebert, R.F., Link, A.N. (2006). Historical Perspectives on the Entrepreneur, in Foundations and Trends in Entrepreneurship, Vol. 2, no. 4: 261-408.

Holcomb TR, Ireland RD, Holmes MR, et al. (2009) Architecture of Entrepreneurial Learning: Exploring the Link among Heuristics, Knowledge, and Action. Entreprenership Theory and Practice, 33: 167-192.

Katz, J.A. (2003). A chronology and intellectual trajectory of American Entrepreneurship education, Journal of Business Venturing, Vol. 18: 283-300.

Kirzner, I.M. (1985). Discovery and the Capitalist Process. Chicago: University of Chicago press.

Kim, W.C., Mauborgne, R., (2005), Blue Ocean Strategy; how to create uncontested market space and make the competition irrelevant, Harvard Business School Press, Boston, MA. 
Lourenco, F., Jones, O., and Jayawarna, D. (2013). Promoting sustainable development: the role of entrepreneurship education. International Small Business Journal, 31. 841-865

Lucas, J. (2011). Manufacturing for export: make or break for the British economy, British Chambers of Commerce, August 2011.

Martin, R. (2010). Beyond the Numbers: Building Your Qualitative Intelligence. Magazine, Spring 2010.

Martin, R. (2013a). The Future of Business and the Role of Business Education, Academy of Management Conference, Orlando, 2013.

Martin, R. (2013b). The future of Management Education, Thinkers 50 Forum, London, 2013.

Mintzberg H (2004) Managers Not Mbas. A Hard Look at the Soft Practice of Managing and Management Development. San Francisco, CA: Berrett-Koehler Publishers, Inc.

Salter, A.J., Martin, B.R. 2001. The economic benefits of publically funded basic research: a critical review, Research Policy, Vol. 30, 509-532.

Shane, S. (2007). The Illusions of Entrepreneurship, Yale University Press, Boston, MA, USA.

Kayes DC (2002) Experiential Learning and Its Critics: Preserving the Role of Experience in Management Learning and Education. Academy of Management Learning and Education 1(2): 137-149.

Kitchener, R. (2001). A treatise on political economy; or the production distribution and consumption of wealth. Jean-Baptiste Say .Translated from the fourth edition of the French. Batoche Books.

Kolb DA (1984) Experiential Learning-Experiences as the Source of Learning and Development. Englewood Cliffs, NJ: Prentice-Hall. 
Kuznets, S. (1971). Nobel Lectures, Economics 1969-1980, Editor Assar Lindbeck, World Scientific Publishing Co., Singapore, 1992

Starkey, K., Hatchuel, A., \& Tempest, S. (2004). Rethinking the business school. Journal of Management Studies, 41,1521-1532.

Wainer, R. (2009). Stronger Together: Businesses and Universities in Turbulent Times, Confederation for British Industry Higher Education Task Force, UK.

Wilson, T. (2012). A Review of Business- University Collaboration, Report for Business Innovation and Skills, London, UK.

Witty, A. (2013). Encouraging a British Invention Revolution: Sir Andrew Witty's Review of Universities and Growth. Report for Business Innovation and Skills, London, UK.

Young, L (2013). Growing Your Business, Report for Business Innovation and Skills, London, UK. 